\title{
Kadın Öğretmenlerde Ruminasyon İle Çözüm Odaklı Düşünme Arasındaki İlişkide Psikolojik Esnekliğin Aracı Rolü*
}

The Mediating Role of Psychological Flexibility in The Relationship Between Rumination and Solution-Focused Thinking in Female Teachers

\section{Sümeyra YAŞAR ${ }^{[1]}$ Fuat AYDOĞDU[2]}

Başvuru Tarihi:15 Aralık 2021

Bu araştırmada kadın öğretmenlerde ruminasyon ile çözüm odaklı düşünme arasındaki ilişkide psikolojik esnekliğin aracı rolünü incelemek amaçlanmıştır. Araştırmanın çalışma grubunu Milli Eğitim Bakanlığı'na bağlı okullarda görev yapan 307 kadın öğretmen oluşturmuştur. Veri toplama araçları olarak Psikolojik Esneklik Ölçeği, Ruminatif Düşünce Biçimi Ölçeği ve Çözüm Odaklı Envanter kullanılmıştır. Araştırmada ruminasyon bağımsız değișken, çözüm odaklı düşünme bağımlı değişken, psikolojik esneklik ise aracı değişken olarak belirlenmiştir. Bu araştırma, değișkenler arasındaki ilişkinin varlığının ve derecesinin incelendiği ilişkisel tarama desenine göre tasarlanmıştır. Aracılık analizleri ise regresyon temelli bootstrapping işlemi esas alınarak yapılmıştır. Yapılan aracılık analizinde doğrudan etkiler incelendiğinde, ruminasyonun psikolojik esnekliği ve çözüm odaklı düşünmeyi yordadığı görülmüştür. Bununla birlikte psikolojik esnekliğin de çözüm odaklı düşünmeyi yordadığı bulunmuştur. Dolaylı etki incelendiğinde ise aracı değişken olan psikolojik esnekliğin modele dâhil edilmesiyle ruminasyon ile çözüm odaklı düşünme arasındaki yol katsayısının anlamlılık düzeyinde azalma olduğu diğer bir deyişle, psikolojik esnekliğin ruminasyon ile çözüm odaklı düşünme arasındaki ilişkide kısmi aracı role sahip olduğu görülmüştür. Bu sonuçlar doğrultusunda kadın öğretmenlerde ruminasyonun, çözüm odaklı düşünme üzerindeki olumsuz etkisinin psikolojik esneklik aracıllı̆ıyla azaltılabileceği söylenebilir.

Anahtar Kelimeler: ruminasyon, psikolojik esneklik, çözüm odaklı düşünme, kadın öğretmenler

Received Date:15 December 2021

In this study, it was aimed to examine the mediating role of psychological flexibility in the relationship between rumination and solution-focused thinking in female teachers. The study group of the research consisted of, 307 female teachers that work in schools affiliated to the Ministry of National Education. Psychological Flexibility Scale, Ruminative Thinking Style Scale and Solution Focused Inventory were used as data collection tools. In the study, rumination was determined as the independent variable, solution-focused thinking as dependent variable, and psychological flexibility as mediating variable. This research was designed according to correlationel survey design, in which the existence and level of relationship between variables was examined. Mediation analyzes were performed on the basis of regression-based bootstrapping. As a result of the findings when the direct effects were examined, it was seen that rumination predicted psychological flexibility and solution-focused thinking. In addition, it was found that psychological flexibility also predicted solution-focused thinking. When the indirect effect was examined, it was seen that the path coefficient between rumination and solution-focused thinking decreased with the inclusion of psychological flexibility, which is a mediating variable in the model. In other words, psychological flexibility had a partial mediating role in the relationship between rumination and solution-focused thinking. In line with these results, it can be stated that the negative effect of rumination on solution-focused thinking can be reduced through psychological flexibility in woman teachers.

Keywords: rumination, psychological flexibility, solution-focused thinking, female teachers esnekliğin aracı rolü. Humanistic Perspective, 4 (1), 126-145. https://doi.org/10.47793/hp.1037046

*Bu çalışmanın özeti 1-3 Eylül 2021 tarihinde Kıbrıs Sağlık ve Toplum Bilimleri Üniversitesi'nde düzenlenen VII. Uluslararası TURKCESS Eğitim ve Sosyal Bilimler Kongresi'nde sözlü bildiri olarak sunulmuştur.

[1] Doktora Öğrencisi | Yıldız Teknik Üniversitesi | Rehberlik ve Psikolojik Danışmanlık | İstanbul | Türkiye | ORCID: 0000-0003-0677-6590 | smyraysr18@gmail.com [2] Doktora Öğrencisi | Hacettepe Üniversitesi | Rehberlik ve Psikolojik Danışmanlık | Ankara | Türkiye | ORCID: 0000-0002-5986-5645 


\section{GíRİs}

$\mathrm{P}$

roblemler ve stres kaynakları insan hayatında her zaman var olan, ne zaman ve ne şekilde bireyin karşısına çıkabileceği, etkilerinin neler olabileceği öngörülemeyen gerçeklerdir. Bu problemler bazen yalnızca birey kaynaklı iken, bazen de tamamen dışsal faktörlerden doğabilmektedir. Herhangi bir sebeple yaşanılan olumsuz durumlar, travmatik olaylar, ani gelişen yaşam değişimleri, ağır sorumluluklar alınması gibi stresli yaşam olayları ve geçiş dönemleri depresyon, kaygı bozuklukları gibi çeşitli psikolojik sorunlara neden olabilmektedir. Bu noktada baş etmesi zor olan tekrarlayıcı düşüncelerin ortaya çıkması, bireylerin sorunların çözümünden uzaklaşmasına ve bunun sonucunda da bu tür tekrarlayıcı düşüncelerin daha da artmasına ve bireyin depresyon, anksiyete, duygu durum bozuklukları gibi sorunlara daha çok sürüklenmesine neden olabilmektedir.

Ruminasyon; düşünmeyi daha karamsar hale getiren, etkili problem çözebilmeye müdahale eden, stresli durumları artıran, kişinin duyguları ve sıkıntıları üzerinde veya yaşadığı olumsuz durumlar üzerinde sürekli tekrar eden, bireyi pasifleștiren bir düşünme tarzıdır (NolenHoeksema vd., 2008). Bu durumlarla başa çıkmada bilişsel terapiler, akılcı duygusal davranışçı yaklaşım gibi kuramların yanı sıra kısa süreli çözüm odaklı yaklaşım da oldukça sık kullanılan yöntemlerden biridir (Laaksonena vd., 2013; Sparrer, 2012).

Bireylerin karşılaştığı stresli durumların ve problemlerin üstesinden gelebilmesinde sorunların çözümüne yönelik yaklaşım biçiminin önemli bir rolü vardır. Bireylerin bu yaklaşım tarzları kişiden kişiye değişmektedir. Kimi insanlar problemler ve nedenleri üzerinde odaklanmaya daha çok zaman harcarken, kimi insanlar daha çok çözüm odaklı düşünme eğilimindedirler. Geleneksel terapi yaklaşımları yüksek oranda geçmişte yaşananları, geçmişin birey üzerindeki etkisini, bireyin ilişkilerini merkeze alır ve bununla birlikte uzun zamana mâl olabilmektedir. Insoo Kim Berg ve Steve De Shazer tarafından zamanı ve maddiyatı azaltmak için geliştirilen çözüm odaklı terapi ise geçmiş yerine şimdiki ana ve bireyin geleceğe yönelik net hedeflerine, problemlerle başa çıkabildiği zamanlara odaklanır (Güner, 2018; Sarıçam, 2014). Çözüm odaklı düşünme, problem odaklı düşünmenin tam tersidir ve hedeflere odaklanma, fark edilmeyen kaynakları fark edebilme, başarmanın yollarını arama gibi unsurları içerir. Bunlar kişiye amaca yönelik değişim yaratmada yardımcı olurlar. Bu unsurlar doğrultusunda çözüm odaklı düşünmenin üç temel alt boyutu bulunmaktadır: Problemin çözüm içeren tarafına odaklanmaya vurgu yapan problemden ayırma, çözüme ilişkin kaynakların olduğunu keşfetmeyi ve esnekliği içeren kaynakları harekete geçirme ve olması istenilen geleceği, hayalleri niteleyen hedefe yönelim alt boyutları yer almaktadır (Grant vd., 2012; Şanal Karahan, 2016).

Bireyin kendi kaynaklarını kullanarak amaçlı ve olumlu bir değişimi hedefleyen, iç dünyasındaki motivasyona odaklanan çözüm odaklı düşünmenin (Oliver ve Charles, 2015) bir 
problemle karşı karşıya kalındığında sorunları aşmak için önemli bir tetikleyiciye dönüştügü söylenebilir. Çünkü, çözüm yerine problemlere daha çok odaklanan ve kendindeki pozitif kaynakları aktifleştiremeyen bireylerde depresyon, anksiyete, ruminasyon, psikolojik katılık gibi sorunların daha çok görüldüğü pek çok araştırmada bulunmuştur (Johnson ve Whisman, 2013; Sarıçam, 2014; Sparrer, 2012; Şanal Karahan, 2016; Yağmur, 2018; Yapan, 2018). Çözüm odaklı düşünmenin ise mutluluk, öznel iyi oluş ve yaşam doyumuyla pozitif yönde ilişkili olduğu (Aydoğdu, 2021; Gündoğdu, 2019; Şanal Karahan, 2016), depresyon, anksiyete, kaygı bozukluklarıyla ise negatif yönde ilişkili olduğu görülmüştür. (Javid vd.,2019; Novella vd. 2020)

Bunların yanı sıra, çözüm odaklı düşünme yaklaşımında dilin kullanımı ve ifade edilişi de önemli bir yere sahiptir. Bireyin problemler karșısında olumlu ve çözüm odaklı bir dil kullanması, güçlü bir motivasyon ve umut kaynağıdır. Çünkü, bireyin problemleri farklı bir bakış açısıyla yeniden çerçeveleyebilmesi için etkin bir dil kullanımı gerekir. Sorunlar yerine çözümlerin dile gelmesi bile tek başına değişim için büyük bir adımdır (Plosker ve Chang, 2014; Sparrer,2012). Burada da vurgu yapıldığı gibi olumlu söylemlerin dile getirilmesi çözüme odaklanabilmek için oldukça önemlidir; fakat sürekli negatif düşünceler üzerinde ruminasyon yapan bir zihinden bunu beklemek güçtür. Buradan hareketle ruminasyon ve çözüm odaklı düşünmenin negatif yönde ilişkili olacağı beklenmektedir ve araştırmanın hipotezlerinden biri olarak bunun test edilmesi amaçlanmıştır.

Son yıllarda "üçüncü dalga" psikoterapilerinden olan ve ilgi gören Kabul ve Kararlılık Terapisi'nin (Acceptance and Commitment Therapy - ACT) önemli kavramlarından biri olan psikolojik esneklik; bireyin yaşadığı olaylar karşısındaki duygu ve düşüncelerini fark etmesi, geçmiş veya gelecek üzerine takılı kalmayıp içinde olduğu anla temas etmesi, karşılaştığı problemleri gerçekçi çözümlerle değerlendirebilmesi ve belirlemiş olduğu değerler doğrultusunda davranışlar gerçekleştirmesidir. Psikolojik esneklik, depresyona ve anksiyeteye sebep olan psikolojik katılığın tam tersidir (Luoma vd., 2010; Stange, Alloy ve Fresco, 2017). Kabul ve kararlılık kuramında, șu an ile bilinçli bir șekilde temas kurmak ve kaygı yaşayan bireylerin duygusal olarak herhangi bir direnç göstermeden bunu kabul etmeleri yönünde cesaretlendirilerek bireylerin psikolojik esnekliklerini artırmak amaçlanır (Hayes, vd, 2006; Luoma ve Vilardaga, 2013). Psikolojik esnekliğin tanımlanmasının konu olduğu güncel bir çalışmada psikolojik esnekliğin Cherry vd. (2021), bireyin yaşadığı duygusal rahatsızlıkları öncelikle fark etmesi, kabul etmesi ve bunlarla yüzleşmesi, bu sıkıntılarla baş edebilmek, duygularını düzenleyebilmek için harekete geçmesi ve kişisel hedefler, sahip olunan değerler doğrultusunda davranış değiştirmesini içerdiği görülmüştür.

Psikolojik esneklik, psikolojik katılığın tam zıttı olacak şekilde ve an ile temas etmek, değerler, davranışsal kararlılık, bağlamsal benlik, ayrışma ve kabul olmak üzere altı boyutta 
açlklanmıștır ve bu boyutlar birbiriyle de ilișkilidir. An'da olma, bireyin șimdi ve burada olma halidir. Değerler, bireyin "bu hayatı ne için yaşıyorum?" sorusunun cevaplarını içerir. Davranışlarda kararlılık, kabul ve kararlılık terapisinin temel hedeflerindendir ve bireyin değerleri doğrultusunda anlamlı davranışlarda bulunabilmesidir. Bağlamsal benlik, gözlemleyen benlik olarak da kullanılan bireyin yaşamı boyunca değişen rollerine, sorumluluklarına, duygularına, düşüncelerine tanıklık eden fakat kendisi hiç değişmeyen asıl benliği içerir. Ayrışma, zihni meşgul eden, yoran sıkıntılı düșünce ve anılardan uzaklaşabilmektir. Kabul ise, hayatın kaçınılmaz gerçekleri olan acılara, üzüntü veren duygulara karşı açık olma onları kabul etme anlamına gelir (Aktepe, 2016; Harris, 2007; Luoma vd.,2010; Karakuş ve Akbay, 2020).

Psikolojik esneklik ruhsal açıdan sağlıklı bir bireyin temel özelliklerindendir ve yokluğu birçok psikopatolojik rahatsızlıklarla ilişkili bulunmuştur. Bireyin şimdiki anla temasının kaybolup geçmişteki acı veren olaylara takılması ve buna yönelik ruminasyonlar yapması, beraberinde geleceğe ilişkin kaygıların artması, depresyon düzeyinin artması ve bireyin yeni davranışlar deneyimlemekten kaçınması bu psikopatolojik rahatsızlıklar arasındadır (Ben vd., 2014; Harris, 2007; Hayes vd., 2006). Psikolojik esnekliğin; ruminatif düşünce biçiminin tam tersi olarak geçmişe değil şu ana odaklanması, tekrar eden olumsuz düşünceler yerine, duygu ve düşüncelerin fark edilerek kabul edilmesi, kişinin değerleri doğrultusunda davranış değişikliğine vurgu yapması ve bunlarla birlikte çözüm odaklı düşüncenin de geçmişteki sorun üzerinde takılmadan, çözüm üzerinde olumlu beklentiye vurgu yapması bu kavramların birbirleriyle önemli ölçüde ilişkili olabileceğini düşündürmektedir. Arslan ve Asıcı (2021) yakın zamanda yaptıkları çalışmalarında mevcut kaynakları harekete geçirerek çözüm odaklı düşünmeyi artırmada farkındalığın ve şimdiki ana odaklanmanın önemli rolü olduğunu görmüşlerdir. Farkındalık ve şimdiki âna odaklanma, psikolojik esnekliğin de temel bileşenleri arasında yer almaktadır.

İlgili alanyazın incelendiğinde, çözüm odaklı düşüncenin temelinde bireyin kendinde var olan kaynaklarını kullanabilmesi, șu ana ve geleceğe odaklanması, potansiyelinin farkında olması ve amacına yönelik bir hedef koyabilmesi olduğu söylenebilir. Sorunlarla karşılaşıldığında kendini gösteren ruminatif düşüncelerin ise bireyin sahip olduğu bu kaynakları kullanabilmesini engellediği ve bireyi depresyona daha çok sürüklediği yapılan çalışmalarda görülmüştür (Harris, 2009; Sarıçam, 2014; Johnson ve Whisman, 2013). Psikolojik katılık, bireyin geçmişte acı veren üzüntülü anılarıyla aşırı meşgul olması, bunlarla ilgili ruminasyonlar yapması ve bunun devamında da geleceğe yönelik kaygı ve endişenin artması sonucu şimdi ve burada olamaması, bugüne odaklanamaması durumudur (Harris, 2009). Bunun tam tersi olan psikolojik esneklik ise, bireyin yaşadığı olaylar karşısındaki duygu ve düşüncelerini fark etmesi, geçmiş veya gelecek üzerine takılı kalmayıp içinde olduğu anla temas etmesi, karşılaştığı problemleri gerçekçi 
çözümlerle değerlendirebilmesidir (Luoma vd., 2010). Bu kapsamda bu kavramlar incelendiğinde psikolojik esnekliğin, ruminasyon ve çözüm odaklı düşünme ile temas eden noktalarının olduğu dikkat çekmiş, farklı çalışmalarda birbirleriyle ilişkili olduğu görülmüştür. Bu araştırmada da birbirleri ile ilişkisi olan ruminasyon ile çözüm odaklı düşünme değişkenleri arasında psikolojik esnekliğin yerini incelemek hedeflenmiștir.

Bu araştırmanın temel amacı kadın öğretmenlerde ruminasyon ve çözüm odaklı düşünme arasındaki ilişkide psikolojik esnekliğin aracı rolünü incelemektir. Araştırmada alanyazındaki çalışmaların sonuçlarından hareketle ruminasyon bağımsız değișken, çözüm odaklı düşünme bağımlı değișken, psikolojik esneklik ise aracı değișken olarak düșünülmüștür.

Araștırmanın amacı doğrultusunda oluşturulan hipotezler șu șekildedir:

$\mathbf{H}_{1}$ : Ruminasyon ile psikolojik esneklik arasında negatif yönde istatistiksel olarak anlamlı ilişki vardır.

$\mathbf{H}_{2}$ : Psikolojik esneklik ile çözüm odaklı düşünme arasında pozitif yönde istatistiksel olarak anlamlı ilişki vardır

H3: Ruminasyon ile çözüm odaklı düşünme arasında negatif yönde istatistiksel olarak anlamlı ilişki vardır.

H4: Ruminasyon ile çözüm odaklı düşünme arasındaki ilişkide psikolojik esneklik aracı role sahiptir.

Çözüm odaklı terapinin zaman ve uygulama açısından daha pratik olması özellikle okul gibi kalabalık ortamlarda etkili bir șekilde kullanılmasına olanak vermektedir. Bu noktada bakıldığında da konuyla ilgili yapılan çalışmaların ağırlıklı olarak ortaöğretim veya yükseköğretim kademesindeki öğrenciler üzerinde gerçekleștiği dikkat çekmiştir. Hızla değișen ve gelişen yaşam koşullarıyla birlikte eğitimdeki ihtiyaçlar ve beraberinde öğretmen rol ve sorumluluklarının da değiștiği görülmektedir. Bunun günümüzdeki en yakın örneği tüm dünyayı ayırt etmeksizin etkileyen, sağlık tehdidinin yanı sıra eğitim sistemini de ciddi boyutlarda değiştiren Covid-19 pandemi sürecidir. $\mathrm{Bu}$ süreçte de görüldüğü gibi öğretmenler eğitim sisteminde ve toplumda oldukça önemli bir öneme sahiptirler. Eğitimin uzun soluklu bir süreç olduğu da göz önüne alındığında, öğretmenlerin hitap ettikleri öğrenciler ve beraberinde onların velileri üzerinde derin izler bırakmaktadırlar. Hem eğitim öğretim sürecinde hem de topluma faydalı insan yetiştirme noktasında belki de en önemli yere sahip olan öğretmenlerin de çözüm odaklı düşünme becerilerini incelemenin önemli olduğu düşünülmektedir. Öğretmenlerin ülkenin farklı noktalarında zorlu şartlarda görev yapmaya çalışmaları, atanma sürecindeki problemler, sürekli değișen eğitim sistemi ve insana hizmet eden bir meslek grubu olması gibi stresli durumlar da öğretmenlerin ruminatif düşünceleri, depresyon ve kaygı düzeylerini tetikleyen unsurlar 
arasında sayılabilir. Bunlarla birlikte, öğretmenlerde kadın istihdamı diğer kamu kurumlarına göre daha yoğundur (Aksöz ve Durkal, 2021). Pek çok epidemiyolojik çalışmada kadınlardaki depresif bozukluğun yaşam boyu yaygınlığının erkeklere göre neredeyse iki kat olduğu bulunmuştur (Hammen, 2003; Mautong, vd, 2021; Noble, 2005). Güncel bir çalışmada ise kadınların hem ruminatif düşünme biçiminin hem de depresyon düzeylerinin erkeklere kıyasla daha yüksek olduğu görülmüștür (Dawson vd., 2022). Bunların yanı sıra, kadın öğretmenlerin iş yaşamında karşılaştıkları sorunları ve kariyer gelişimlerini engelleyen durumları ele alan çalışmaların sonuçları da konunun günden güne önem arz ettiğine dikkat çekmektedir (İnandı ve Tunç, 2012). Ayrıca Covid-19 pandemi sürecindeki uzaktan eğitimde kadın öğretmenlerin hem iş sorumlulukları hem ev ve aile içi sorumluluklarının daha da arttı̆̆ı söylenebilir. Bu ve benzeri pek çok durumun kadınları etkileme düzeyi, sorunlarla baş etme yöntemleri, farkındalık düzeyleri, sorunlara karşı esnek veya katı bir bakış açısıyla yaklaşmaları da değişkenlik göstermektedir. Bu değişkenliklerin, bireyin yaşadığı olaylar karşısındaki duygu ve düşüncelerini fark etmesi, geçmiş veya gelecek üzerine takılı kalmayıp içinde olduğu anla temas etmesi, karşılaştığı problemleri gerçekçi çözümlerle değerlendirebilmesi olarak özetlenebilen psikolojik esneklik (Luoma vd. 2010) düzeyi ile ilişkili olabileceği düşünülmüș ve konunun irdelenmesi gerekliliği doğmuştur.

\section{YÖNTEM}

\section{Araştırma Modeli}

Bu araştırma, değişkenler arasındaki ilişkinin varlığının ve derecesinin incelendiği ilişkisel araştırma desenine göre tasarlanmıştır. İlişkisel araştırma yöntemi iki ya da daha fazla değişkenin tutarlı bir şekilde birlikte değişme örüntüsünü ve bu değişimin düzeyini belirlemek için kullanılır (Creswell, 2012).

\section{Çalışma Grubu}

Araştırmanın çalışma grubunu Milli Eğitim Bakanlığı'na bağlı okullarda görev yapan 307 kadın öğretmen oluşturmaktadır. Katılımcılara ilişkin betimsel istatistikler Tablo 1'de verilmiştir.

\section{Tablo 1}

Katılımcllara ilişskin betimsel istatistikler $(n=307)$

\begin{tabular}{llc}
\hline & Değişkenler & Frekans \\
\hline Yaş & Ort. & 35.41 \\
Mesleki Kıdem Yılı & S & 8.00 \\
& Ort. & 11.58 \\
Medeni Durum & $\mathrm{S}$ & 8.33 \\
& Evli & 184 \\
& Bekâr & 101 \\
Eğitim Durumu & Diğer & 22 \\
& Lisans Mezunu & 236 \\
\hline
\end{tabular}




\section{Veri Toplama Araçları}

Psikolojik Esneklik Ölçeği. Francis vd. (2016) tarafından geliştirilmiştir. Türkçeye uyarlaması Karakuş ve Akbay (2020) tarafından 310 yetişkin bireyin katılımıyla yapılmıştır. Ölçek toplam 28 maddeden ve 5 alt boyuttan oluşmaktadır. Ölçeğin alt boyutları şu şekildedir: Değer ve Değer Doğrultusuna Davranış (10 madde), An'da Olma (7 madde), Kabul (5 madde), Bağlamsal Benlik (3 madde), Ayrışma (3 madde). Model, iyi uyum değerleri ile doğrulanmıștır (KMO=0.789; $\chi^{2}=3096.080 ; p=0.00$ ). Ölçekte faktör yükleri .47 ile .81 arasında değişmektedir ve açıklanan varyans \%60 olarak saptanmıştır. Ölçeğin güvenirlik çalışmasında Cronbach Alpha iç tutarlılık güvenirlik katsayısı .79 olarak hesaplanmıștır. Ölçekten en düşük 28, en yüksek 196 puan alınabilmektedir. Ölçeğin bazı maddeleri tersten kodlanmaktadır $(2,3,5,6,8,18,20,22,23,24$ ve 25). Ölçek alt boyutlarından alınan yüksek puanlar, yüksek psikolojik esnekliği göstermektedir. Bu araştırmada ölçeğin Cronbach Alpha iç tutarlılık güvenirlik katsayısı .84 bulunmuştur.

Ruminatif Düşünce Biçimi Ölçeği. Orijinali Brinker ve Dozois (2009) tarafından geliştirilen Ruminatif Düşünce Biçimi Ölçeği'nin Türkçe formunun geçerlik ve güvenirlik çalışması Karatepe (2010) tarafından yapılmıştır. 350 yetişkin bireyin katılımıyla araştırma yürütülmüştür. Ölçeğin Cronbach Alpha iç tutarlılık güvenirlik katsayısı .90 olarak hesaplanmıștır. Ölçeğin tek faktörlü olduğu ve toplam varyansın \% 63.43'ünü açıkladığı bulunmuştur. Toplam 20 maddelik, tek boyutlu 7'li Likert tipinde bir ölçektir. Ölçekten alınacak en düşük 20 en yüksek puan 140 arasında değişmektedir. Ters madde bulunmamaktadır. Bu araştırmada ölçeğin Cronbach Alpha iç tutarlılık güvenirlik katsayısı 95 bulunmuştur.

Çözüm Odaklı Envanter. Ölçeğin orijinali (Solution-Focused Inventory) bireylerin çözüm odaklı düşüncelerini ölçmek için Grant vd. (2012) tarafından geliştirilmiştir. Ölçek, Türkçe'ye Şanal Karahan ve Hamarta (2015) tarafından uyarlanmıștır. Toplam 12 maddeden ve 3 alt boyuttan oluşan 6'lı Likert tipindedir. Problemden ayırma, hedefe yönelim ve kaynakları harekete geçirme olmak üzere üç faktörden oluşan ölçekte puan aralığı 12 ile 72 arasındadır. Ölçeğin toplamında Cronbach Alpha iç tutarlılık güvenirlik katsayısı. 72 olarak saptanmıştır. $\mathrm{Bu}$ araştırmada ölçeğin Cronbach Alpha iç tutarlılık güvenirlik katsayısı .81 bulunmuştur.

\section{Veri Toplama Süreci}

Veri toplama araçları çevrimiçi ortama aktarılmış ve Google Form aracılı̆̆ıyla katılımcılara ulaştırılmıştır. Çevrimiçi ortama aktarılan formun açıklama kısmında açıklamanın içeriğiyle ilgili detaylı bilgi verilmiş, katılmanın gönüllülük esasına dayalı olduğu belirtilmiş ve elde edilecek verilerin sadece bilimsel bir amaç için kullanılacağı, verilerin genel değerlendirmeye tabi tutulacağı, araştırmanın kapsamı ve kimler tarafından yürütüleceği hakkında detaylı bilgi verilmiştir. Katılımcılardan bu bilgileri okuyup, anladıkları ve çalışmaya gönüllü olarak 
katıldıklarını beyan edecekleri 'Okudum ve anladım' ibaresi eklenmiş ve gönüllülük gösterenler araştırmaya dahil edilmiştir.

\section{Etik Onay}

Araştırma için Yıldız Teknik Üniversitesi Sosyal ve Beşeri Bilimleri Yayın Etik Kurul Başkanlığı'ndan etik kurul onayı alınmıştır (24.06.2021- Toplantı No:2021/04).

\section{Verilerin Analizi}

Araştırma kapsamında Google Formlar aracıllğıyla elde edilen veriler SPSS 26.0 PROCESS kullanılarak analiz edilmiştir. Önce verilerin normal dağılım gösterip göstermediğini analiz etmek amacıyla normallik testi yapılmıştır. Bu araştırmada da veri setinin normal dağılım gösterip göstermediğini test etmek için basıklık ve çarpıklık katsayıları incelenmiştir (Tabachnik ve Fidel, 2007). Tablo 2'de değişkenlerin çarpıklık ve basıklık değerleri ile betimsel istatistikleri verilmiştir.

\section{Tablo 2}

Değişkenlere ait çarpıklık ve basıklık değerleri ile betimsel istatistikler

\begin{tabular}{lccccccc}
\hline Değişkenler & $\boldsymbol{n}$ & Ort. & En Düşük & En Yüksek & s & Çarpıklık & Basıklık \\
\hline Ruminasyon & 307 & 92.01 & 24 & 140 & 24.42 & -0.239 & -0.487 \\
Psikolojik Esneklik & 307 & 131.30 & 87 & 193 & 20.11 & 0.304 & -0.373 \\
Çözüm Odaklı Düşünce & 307 & 54.25 & 26 & 72 & 8.45 & -0.409 & 0.011 \\
\hline
\end{tabular}

Tablo 2 incelendiğinde kullanılan ölçme araçlarının toplam puanlarının çarpıklık ve basıklık katsayılarının -1.5 ila +1.5 arasında değiştiği görülmektedir. Sonuç olarak ölçeklerden elde edilen puanların normal dağılım özelliği gösterdiği kabul edilmiştir (Tabachnick ve Fidel, 2007). Araştırma kapsamında aracılık testine geçilmeden önce değişkenlere ilişkin toplam puanlar arasındaki Pearson Çarpım Momentler Korelasyon Katsayısı incelenmiştir.

Bu işlemlerin ardından Hayes'in (2017) önerileri esas alınarak regresyon temelli aracılık analizleri yapılmıştır. Aracılık etkisinin anlamlılığını kontrol edebilmek amacıyla bootstrapping işlemi uygulanmıştır. Doğrudan ve dolaylı etkilerin anlamlılığını örneklem sayısını artırarak tekrar test etme işlemi olan bootstrapping işlemi sonucunda alt ve üst güven aralıkları sınırı belirlenir ve dolaylı etkinin anlamlı olabilmesi için bu sınırın sıfırı kapsamaması gerekmektedir (Hayes, 2017). Bu araştırmada da 5000 bootstrapping (yeniden örnekleme) yapılarak alt ve üst güven aralıkları ve boostrapp katsayısı belirlenmiştir. 


\section{BULGULAR}

Araştırma kapsamında ele alınan değişkenler arasındaki ilişsinin derecesini ve yönünü incelemek amacıyla öncelikle Pearson Çarpım Momentler Korelasyon Katsayısı hesaplanmış ve sonuçlar Tablo 3'te sunulmuştur.

\section{Tablo 3}

Değişkenler arasındaki ilişkilere ait Pearson Çarpım Momentler Korelasyon Katsayıları

\begin{tabular}{lcccc}
\hline Değişkenler & $\mathbf{1}$ & $\mathbf{2}$ & Ort. & s \\
\hline 1- Ruminasyon & & & 92.01 & 24.42 \\
2- Psikolojik Esneklik & $-.274^{* *}$ & & 131.30 & 20.11 \\
3- Çözüm Odaklı Düşünce & $-.488^{* *}$ & $.583^{* *}$ & 54.25 & 8.45 \\
\hline
\end{tabular}

Tablo 3 incelendiğinde ruminasyonun psikolojik esneklik $(r=-.274 ; p<.01)$ ile negatif yönde düşük düzeyde; çözüm odaklı düşünce $(r=-.488 ; p<.01)$ ile negatif yönde orta düzeyde anlamlı ilişkiye sahip olduğu görülmektedir. Bununla birlikte psikolojik esneklik ile çözüm odaklı düşünme arasında da pozitif yönde orta düzeyde anlamlı ilişki olduğu görülmektedir $(r=.583$; $p<.01)$.

Değişkenler arası ilişkilerin incelenmesinin ardından aracılık etkisi test edilmiş, değişkenler arasındaki yol katsayıları, dolaylı etki ve bootstrapping sonuçları Tablo 4'te verilmiştir.

\section{Tablo 4}

Aracılık modeline ilişskin yol katsayıları, dolaylı etki ve bootsrapping sonuçları

\begin{tabular}{|c|c|c|c|c|c|c|c|}
\hline \multirow{3}{*}{\multicolumn{3}{|c|}{ Tahmin Değişkenleri }} & \multicolumn{5}{|c|}{ Sonuç Değişkenleri } \\
\hline & & & \multicolumn{2}{|c|}{ Psikolojik Esneklik } & \multicolumn{3}{|c|}{ Çözüm Odaklı Düşünce } \\
\hline & & & \multirow{2}{*}{$\begin{array}{c}\beta \\
-.23^{* * *}\end{array}$} & \multirow{2}{*}{$\begin{array}{r}\text { SH } \\
.05\end{array}$} & \multicolumn{2}{|r|}{$\beta$} & \multirow{2}{*}{$\begin{array}{c}S H \\
-\end{array}$} \\
\hline Ruminasyon (a yol & & & & & & - & \\
\hline$R^{2}$ & & & \multicolumn{2}{|l|}{.08} & \multicolumn{2}{|r|}{-} & \\
\hline \multicolumn{3}{|c|}{ Ruminasyon (c yolu) } & - & \multirow[t]{2}{*}{-} & & $-.49^{* * *}$ & \multirow[t]{2}{*}{.017} \\
\hline \multicolumn{3}{|c|}{$R^{2}$} & - & & \multicolumn{2}{|r|}{.24} & \\
\hline \multicolumn{3}{|c|}{ Ruminasyon (c1 yolu) } & \multicolumn{2}{|l|}{-} & \multicolumn{2}{|r|}{$-.35^{* * *}$} & .01 \\
\hline \multicolumn{3}{|c|}{ Psikolojik Esneklik (b yolu) } & \multicolumn{2}{|l|}{-} & \multicolumn{2}{|r|}{$.49^{* * *}$} & .02 \\
\hline \multicolumn{3}{|l|}{$R^{2}$} & \multicolumn{2}{|l|}{-} & \multicolumn{2}{|r|}{.46} & \\
\hline \multicolumn{3}{|l|}{ Dolaylı etki } & \multicolumn{2}{|l|}{-} & \multicolumn{3}{|c|}{$-.13(-.20,-.07)$} \\
\hline Değişkenler & B & SH & $\beta$ & $\mathbf{t}$ & $p$ & $R^{2}$ & $\% 95$ GA \\
\hline a yolu & -.23 & .045 & -.27 & -4.98 & .000 & .08 & $-.32,-.14$ \\
\hline b yolu & .20 & .019 & .49 & 11.03 & .000 & .46 & $.17, .24$ \\
\hline c yolu & -.17 & .017 & -.49 & -9.76 & .000 & .24 & $-.20,-.13$ \\
\hline$c^{1}$ yolu & -.12 & .015 & -.35 & -8.06 & .000 & .46 & $-.15,-.10$ \\
\hline Dolaylı etki & -.04 & .031 & -.13 & - & .000 & - & $-.20,-.07$ \\
\hline
\end{tabular}


Tablo 4'te Ruminasyon ile psikolojik esneklik arasındaki ilișkide psikolojik esnekliğin aracı rolüne ilişkin yol katsayıları, dolaylı etki ve bootsrapping sonuçları yer almaktadır. İlk olarak $\mathrm{H}_{1}$ (Ruminasyon $\rightarrow$ Psikolojik Esneklik a yolu) test edilmiş ve ruminasyonun psikolojik esnekliği yordadığı $(\beta=-.27, \% 95 \mathrm{BCA} ; \mathrm{SH}=.05 ; \mathrm{GA}=[-.32,-.14])$ görülmüştür. Daha sonra araştırmanın ikinci hipotezi $\mathrm{H}_{2}$ (Psikolojik Esneklik $\rightarrow$ Çözüm Odaklı Düşünme b yolu) test edilmiş ve psikolojik esnekliğin çözüm odaklı düşünmeyi yordadığı $(\beta=-.49$, \%95 BCA; SH=.02; GA = $[-.17,-.24])$ görülmüştür. Sonrasında $\mathrm{H}_{3}$ (Ruminasyon $\rightarrow$ Çözüm Odaklı Düşünme c yolu) test edilmiş ve ruminasyonun çözüm odaklı düşünmeyi yordadığı $(\beta=-.49$, \%95 BCA; SH=.02; GA = [.20, .13]) görülmüştür. Araştırmanın son hipotezi $\left(\mathrm{H}_{4}\right)$ ise ruminasyon ve çözüm odaklı düşünme arasındaki ilişkide psikolojik esnekliğin aracı rolü olduğudur. Aracı değişken olan psikolojik esnekliğin modele dahil edilmesi ile ruminasyon değişkeninden çözüm odaklı düşünmeye giden yol katsayısının hala anlamlı olduğu görülmüștür $(\beta=-.35$; $\mathrm{p}<0.01)$. Psikolojik esneklik, ruminasyon ile birlikte çözüm odaklı düşünme üzerindeki değişimin (varyansın) \%46'sını açıkladığı görülmektedir. Ruminasyonun psikolojik esneklik vasıtasıyla çözüm odaklı düşünme üzerindeki dolaylı etkinin anlamlılığını tespit etmek amacıyla Bootstrapp yapılmış ve dolaylı etkinin anlamlı olduğu görülmüştür ( $\beta=-.13, \% 95 \mathrm{BCA}$; SH=.03; GA = [-.20, -.07]). Ayrıca aracı değişken olarak belirlenen psikolojik esnekliğin modele girmesiyle, ruminasyon ile çözüm odaklı düşünme arasındaki anlamlı ilişkinin yol katsayısında azalma olduğu görülmüştür ( $c^{1}=-.49$ 'dan $-.35^{\prime} \mathrm{e}$, $p<.05)$. Bu sonuçlar ruminasyon ve çözüm odaklı düşünme arasındaki ilişkide psikolojik esnekliğin kısmi aracı role sahip olduğunu göstermektedir (Baron ve Kenny, 1986). Bu durumda araştırmanın son hipotezinin de desteklendiği görülmektedir. Aracılık modeli şekil 1'de sunulmuştur.
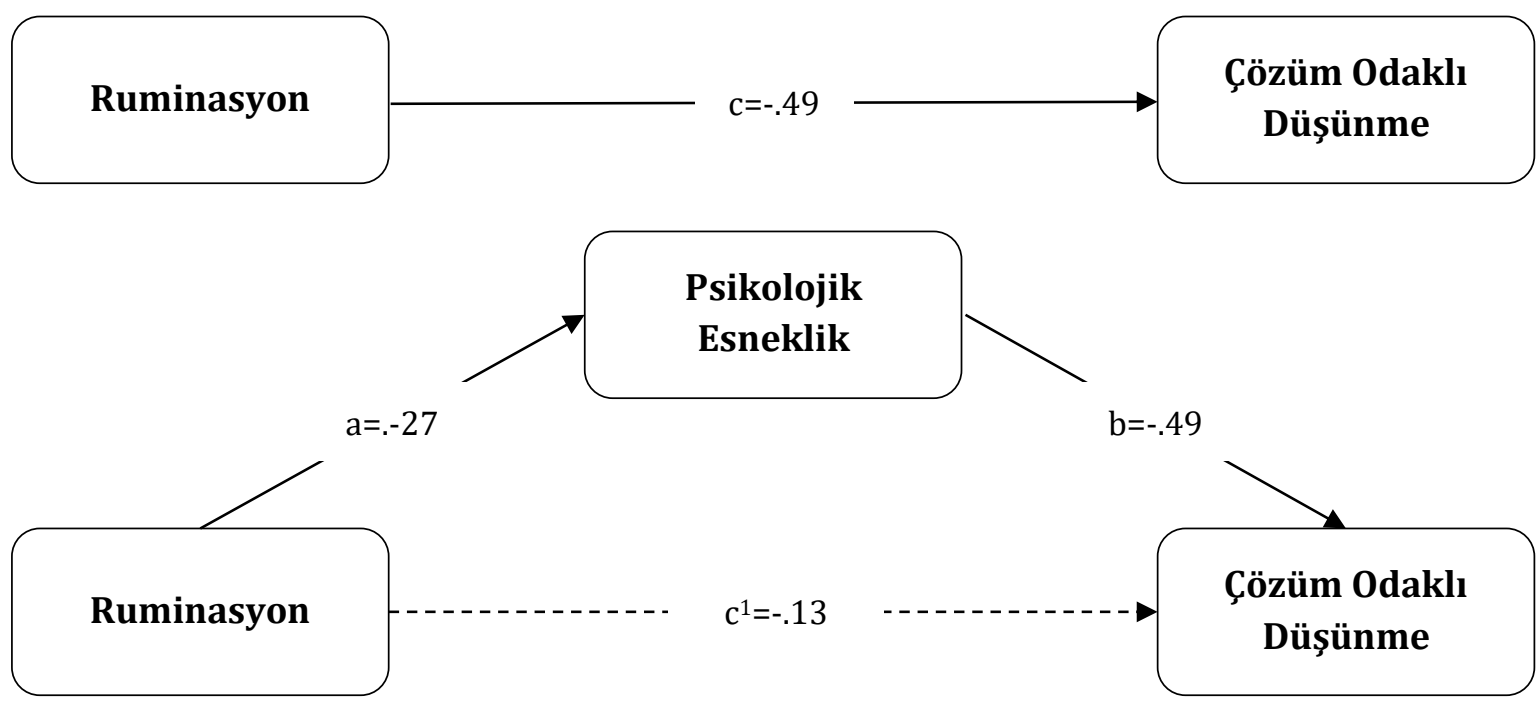

Şekil 1. Ruminasyonun Psikolojik Esneklik Aracıllğıyla Çözüm Odaklı Düşünmeyi Yordaması

Not: $\mathrm{R}^{2}=.46 ; \mathrm{F}_{(2,304)}=127.485 ; p<.001$ 
Şekil 1 incelendiğinde, Ruminasyon ile çözüm odaklı düşünme arasında psikolojik esnekliğin kısmı aracı role sahip olduğu görülmektedir. Bir başka deyişle ruminasyonun, bireylerin çözüm odaklı düşünebilmeleri üzerindeki olumsuz etkisinin bireylerin psikolojik esneklik düzeyleri aracılığıyla azaltılabileceği söylenebilir. Aracılık modeli sonucunda psikolojik esneklik, ruminasyon ile birlikte çözüm odaklı düşünme üzerindeki varyansın \%46'sını açıkladığı görülmektedir $\left(\mathrm{R}^{2}=.44 ; \mathrm{F}_{(2,304)}=127.485 ; p<.001\right)$.

\section{TARTIŞMA, SONUÇ VE ÖNERÍLER}

Bu araştırmanın sonucunda kadın öğretmenlerde ruminasyon ile çözüm odaklı düşünme arasındaki ilişkide psikolojik esnekliğin kısmı aracı role sahip olduğu bulunmuştur. Bir başka ifadeyle, ruminasyonun kadın öğretmenlerin çözüm odaklı düşünebilmeleri üzerindeki olumsuz etkisi psikolojik esneklik aracılığıyla azaltılabileceği söylenebilir. Araştırmanın bu temel amacı doğrultusunda araştırmada öncelikle değişkenler arasındaki ilişkiler incelenmiştir. Değisşkenler arasındaki ilişkiler sonucunda, ruminasyon ile psikolojik esneklik arasında negatif yönde düşük düzeyde anlamlı ilişki olduğu bulunmuştur. Bu sonuç araştırmanın birinci hipotezinin $\left(\mathrm{H}_{1}\right)$ doğrulandığını göstermektedir. Olumsuz ve tekrarlayıcı düşünceler olarak özetlenebilen ruminasyonun nasıl ve neden geliştiği sıklıkla incelenen önemli konulardandır (Önder ve Utkan, 2018; Smith ve Alloy, 2009). Ögel (2012) araştırmasında, ruminatif düşüncelerin artmasıyla bireyin gerçekliğinin bu düşüncelere dönüştüğünü ve dolayısıyla çevresine yönelik farkındalığının gittikçe azalacağına değinmiştir. Ruminasyonun bilinçli farkındalık ve algılanan stress arasındaki ilişkide aracılık etkisinin incelendiği bir çalışmada da (Cenkseven Önder ve Utkan, 2018) kısmı aracılığının olduğu görülmüştür.

Alanyazın incelendiğinde ruminasyon ile farkındalık arasında negatif yönde anlamlı ilişki olduğunu gösteren pek çok çalışma bulunmaktadır (Cenkseven Önder ve Utkan, 2018; Michalak, vd., 2011; Raes ve Williams, 2010). Farkındalık ve anda olma ise psikolojik esnekliğin temel unsurları arasında yer almaktadır ve psikolojik esneklik düzeyinin artırılmasında gereklidir (Bilgen, 2021). Bu noktadan bakıldığında ruminatif düşünceler bireyin farkındalık düzeyini azaltmakta, ki bu durum da psikolojik esnekliği azaltmaktadır. Yasisnski vd. (2020) depresyon tanısı almış bireylerle yaptıkları yakın zamanlı araştırmalarında psikolojik esnekliğin yüksek olmasının, ruminatif düşüncelere karşı bir tampon görevinde olduğunu ve bu durumun depresyondaki bireylere uygulanan bilişsel davranışçı terapide oldukça iyi sonuçlar sağladığını bulmuşlardır. Bunlara ek olarak ruminasyonun, psikolojik esnekliğin tam tersi olan psikolojik katılık ile pozitif yönde anlamlı düzeyde ilişkisinin olduğu da bulunmuştur (Kashdan ve Rottenberg, 2010). Çalışan kadınların psikolojik esneklik düzeylerinin incelendiği bir çalışmada ise kadınların psikolojik esneklik düzeylerinin mesleki tükenmişlikle ilişkili olduğu bulunmuştur (Nevanpera vd., 2013). Dolayısıyla bu araştırmanın birinci hipotezini oluşturan ruminasyon ve 
psikolojik esneklik arasında negatif yönde anlamlı ilişkinin olduğu konuyla ilgili benzer temada yapılmış önceki çalışmaların bulgularıyla desteklenmiştir.

Araştırmanın diğer bir sonucunda psikolojik esneklik ile çözüm odaklı düşünme arasında pozitif yönde orta düzeyde anlamlı ilişki olduğu bulunmuştur. Bu sonuç araştırmanın ikinci hipotezinin $\left(\mathrm{H}_{2}\right)$ doğrulandığını göstermektedir. Kashdan ve Rottenberg (2010) bir araştırmalarında çözüm odaklı düşünme stili ile psikolojik iyi oluş ve psikolojik esnekliğin pozitif yönde anlamlı ilişkili olduğuna yönelik benzer sonuca ulaşmıştır. McCracken vd.'nin (2018) bir araştırmasında intihar düşüncesi ile psikolojik esneklik arasında negatif bir ilişki saptanmıştır. İntihar düșüncesi, problemleri olan bireylerin tüm yollarının tıkanması durumunda tetiklenebilir. Bunun aksine her zaman alternatif yolların olduğu bir yaklaşımı temel alan çözüm odaklı düşünce intihar düşüncesi ile zıtlık gösterdiği bilindiğinden psikolojik esneklik ile çözüm odaklı düşünce arasındaki ilişkinin doğrulanması önemlidir.

Araștırmanın diğer bir sonucunda, ruminasyon ile çözüm odaklı düşünme arasında negatif yönde orta düzeyde anlamlı ilişki olduğu bulunmuştur. Bu sonuç araştırmanın üçüncü hipotezinin $\left(\mathrm{H}_{3}\right)$ doğrulandığını göstermektedir. İlgili değişkenlerin ele alındığı deneysel bir çalışmada, çözüm odaklı kısa süreli psikolojik danışma yönelimli müdahale programının bireylerin ruminasyon düzeyini azaltmada oldukça etkili bir yaklaşım olduğu bulunmuştur (Sarıçam, 2014). Bunun yanı sıra, ruminasyonun bireylerin stres ve depresyonu artırarak etkili problem çözme becerilerine müdahale ettiği de ortaya konulmuştur (Nolen-Hoeksema, 2000). Ruminasyonun, sorunlarla başa çıkma kapasitesini önemli ölçüde zayıflattığı, kaygı ve depresyonu artırtığı göz önüne alındığında (Arnarson vd., 2016; Grassia ve Gibb,2008) bunun bireyin yaşadığı sorunlara yönelik çözüm üretebilmesinde, etkili problem çözebilmesinde ve esnek düşünebilmesinde ciddi bir engel olduğu söylenebilir. Esneklikten uzak bir düşünce sistemiyle karakterize olan bireylerin, uyumsuz başa çıkma ve problem odaklı davranışlar sergileme eğiliminde oldukları önceki araștırmalarda da görülmüştür (Yasinski vd.,2020; Kasch vd., 2002).

Araştırmanın temel amacı kapsamında kadın öğretmenlerin ruminasyon ile çözüm odaklı düşünmeleri arasındaki ilişkide psikolojik esnekliğin aracı rolü saptanmıştır. Bu bulgu araştırmanın son hipotezinin $\left(\mathrm{H}_{4}\right)$ de doğrulandığını göstermektedir. Psikolojik esneklik, son yıllardaki üçüncü dalga psikoterapi akımları arasında yer alan Kabul ve Kararlılık Terapisi'nin (ACT) temelini oluşturmaktadır ve psikolojik iyi oluşla pozitif yönde ilişkiliyken (Gloster vd., 2017; Stabbe vd.,2019) depresyon ve anksiyeteye karşı da koruyucu rolde olduğu bulunmuştur (Pakenham vd., 2020). Öcel (2017), kanser tanısı almış olan hastalarla yaptığı çalışmasında ise, bu durumun olumsuz sonuçlarının üstesinden gelebilmede, problemlerler ve stresli durumlarla baş edebilmede psikolojik esnekliğin ne kadar gerekli olduğuna dikkat çekmiş; bilinçli farkındalık 
ile psikolojik iyi oluș arasındaki ilișkide psikolojik esnekliğin düzenleyici bir rolü olduğunu bulmuştur.

Sonuç olarak bu araştırmada ruminasyonun, kadın öğretmenlerin çözüm odaklı düşünmelerini gerek doğrudan gerekse psikolojik esneklik aracılığıyla etkilediği bulunmuştur. Bu sonuçtan hareketle kadın öğretmenlerin ruminatif düşüncelerinin çözüm odaklı düşünmeleri üzerindeki olumsuz etkisini azaltmak, kadın öğretmenlerin psikolojik esneklik düzeylerini arttırmak ile mümkün görünmektedir. Bu yüzden okullarda özellikle kadın öğretmenlerin psikolojik esneklik düzeylerini arttıracak psikolojik esneklik konulu psikoeğitim veya psikolojik danışma grupları oluşturmak, psikolojik esneklik hakkında bilgilendirme yoluyla farkındalık kazandırmak gibi çalışmaların öncelenmesi önemlidir. Bu araştırmada ayrıca ruminasyonun psikolojik esneklik ile birlikte çözüm odaklı düşünme üzerindeki değişimin \%46'sını açılkladığı bulunmuştur. Bu bulgu öğretmenlerin çözüm odaklı düşünmelerini geliştirmek için tasarlanacak müdahale programlarında ruminasyonu azaltacak, psikolojik esnekliği arttıracak faaliyetlerin birlikte ele alınması konusunda alanyazına önemli katkılar sunan bir modeli sınadığı için önemlidir. Bunun dışında bu araştırmada ruminasyon ve çözüm odaklı düşünme arasındaki ilişkiyi etkileyebilecek psikolojik esneklik dışında farklı değişkenlerin aracılılık etkisini de incelemenin, araştırmanın bağımlı değişkeni olarak belirlenen çözüm odaklı düşünmenin doğasını anlamada önemli katkılar sunacağı düşünülmektedir.

Bu çalışma yaş ortalaması 35.41 \pm 8.00 olan kadın öğretmenlerin oluşturduğu özel bir örneklemle yürütüldüğü ve kesitsel yönteme dayandığı unutulmamalıdır. Elde edilen bu sonuçlar belirtilen yöntem ve çalışma grubu çerçevesiyle sınırlıdır. Farklı örneklem ve yaş grupları üzerinde, boylamsal veya deneysel yöntemlerin kullanılarak ilgili değişkenlerin test edilmesi konunun derinlemesine incelenmesi açısından önerilmektedir. 


\section{KAYNAKÇA}

Aksöz, F., \& Durkal, M. E. (2021). Çalışma hayatında kadınların karşılaştıkları sorunlar: Kayseri ilinde çalışan kadın öğretmenler üzerine bir araştırma. Erciyes Üniversitesi İktisadi ve İdari Bilimler Fakültesi Dergisi, (59), 141-176. https://doi.org/10.18070/erciyesiibd.801617

Aktepe, M. (2016). Bipolar bozukluk hastalarında psikolojik esneklik [Tıpta uzmanlik tezi]. Bakırköy Prof. Dr. Mazhar Osman Ruh Sağlı̆̆ı ve Sinir Hastalıkları Eğtim ve Araştırma Hastanesi, Psikiyatri Kliniği.

Al-Ma'seb, H. (2018). Social support as a predictive factor: Solution-focused thinking in clinical social work. International Social Work, 63(3), 323-336. https://doi.org/10.1177/0020872818799432

Arnarson, E. Ö., Matos, A. P., Salvador, C., Ribeiro, C., de Sousa, B., \& Craighead, W. E. (2016). Longitudinal study of life events, well-being, emotional regulation and depressive symptomatology. Journal of Psychopathology and Behavioral Assessment, 38(2), 159-171. https://doi.org/10.1007/s10862-015-9524-8

Arslan, Ü., \& Asıcl, E. (2021). The mediating role of solution focused thinking in relation between mindfulness and psychological well-being in university students. Current Psychology, 110. https://doi.org/10.1007/s12144-020-01251-9

Aydoğdu, F. (2021). Öğretmenlerde çözüm odakli düşünme ile mutluluk ilişkisinde sürekli umut ve yaşam doyumunun araci rolü. Psikiyatride Guncel Yaklasimlar - Current Approaches in Psychiatry, 13(Ek 1), 337-360. https://doi.org/10.18863/pgy.983099

Baron, R. M., \& Kenny, D. A. (1986). The moderator-mediator variable distinction in social psychological research: Conceptual, strategic, and statistical considerations. Journal of Personality and Social Psychology, 51(6), 1173-1182. https://doi.org/10.1037//00223514.51.6.1173

Ben-Itzhak, S., Bluvstein, I., \& Maor, M. (2014). The Psychological Flexibility Questionnaire (PFQ): Development, reliability and validity. Webmed Central Psychology, 5(4), 1-10.

Bilgen, İ. (2021). Terapide psikolojik esneklik kabul ve adanmışlık terapisi. Epsilon.

Brinker J. K., \& Dozois J. A. (2009). Ruminative thought style depressed mood. Journal of Clinical Psychology. 65(1),1-19. https://doi.org/10.1002/jclp.20542

Butler L. D., \& Nolen-Hoeksema, S. (1994). Gender differences in response to depressed mood in a college sample. Sex Roles, 30, 331-346.

Cankseven Önder, F., \& Utkan, Ç. (2018). Bilinçli farkındalık ve algılanan stres ilişskisinde ruminasyon ve olumsuz duygu düzenlemenin aracı rolü. Mersin Üniversitesi Eğitim Fakültesi Dergisi, 14(3), 1004-1019. https://doi.org/10.17860/mersinefd.444876

Cherry, K. M., Vander Hoeven, E., Patterson, T. S., \& Lumley, M. N. (2021). Defining and measuring "psychological flexibility": A narrative scoping review of diverse flexibility and rigidity constructs and perspectives. Clinical Psychology Review, 101973. https://doi.org/10.1016/j.cpr.2021.101973

Çokluk, Ö., Şekercioğlu, G., \& Büyüköztürk, Ș. (2012). Sosyal bilimler için çok değişsenli istatistik: SPSS ve LISREL uygulamaları. Pegem Akademi.

Creswell, J. W. (2012). Educational research: Planning, conducting, and evaluating quantitative. Pearson.

Dawson, G. C., Adrian, M., Chu, P., McCauley, E., \& Vander Stoep, A. (2022). Associations between sex, rumination, and depressive symptoms in late adolescence: A four-year longitudinal investigation.Journal of Clinical Child \& Adolescent Psychology, 1-11. https://doi.org/10.1080/15374416.2021.2019049 
Francis, A. W., Dawson, D. L., \& Golijani-Moghaddam, N. (2016). The development and validation of the comprehensive assessment of acceptance and commitment therapy processes (CompACT). Journal of Contextual Behavioral Science, 5, 134-145. https://doi.org/10.1016/j.jcbs.2016.05.003

Gloster, A.T., Meyer, A.H., \& Lieb, R. (2017). Psychological flexibility as a malleable public health target: Evidence from a representative sample. Journal of Contextual Behavioral Science, 6 (2), 166-171. https://doi.org/10.1016/j.jcbs.2017.02.003

Grant, A. M., Cavanagh, M. J., Kleitman, S., Spence, Gordon, Lakato, M., \& Yu, N. (2012). Development and validation of the Solution-Focused Inventory. The Journal of Positive Psychology, 7(4), 334-348. https://doi.org/10.1080/17439760.2012.697184

Grassia, M., \& Gibb, B. E. (2008). Rumination and prospective changes in depressive symptoms. Journal of Social and Clinical Psychology, 27(9), 931-948. https://doi.org/10.1521/jscp.2008.27.9.931

Gündogdu, R. (2019). The effect of solution-focused group counseling with psychological counselor candidates on solution-focused tendency and satisfaction with life. Journal of Education and E-Learning Research, 6(1), 26-37. https://doi.org/10.20448/journal.509.2019.61.26.37

Güner, O. (2018). Çözüm bende saklı. Ankara.

Hammen, C. (2003). Interpersonal stress and depression in women.Journal of affective disorders, 74(1), 49-57. https://doi.org/10.1016/s0165-0327(02)00430-5

Harris, R. (2007). ACT made simple: an easy-to-read primer on Acceptance and Commitment Therapy. New Harbinger Publication, 9 (13), 26-30.

Hayes, A. F. (2017). Introduction to mediation, moderation, and conditional process analysis: $A$ regression-based approach. Guilford publications.

Hayes, S. C., Luoma, J. B., Bond, F. W., Masuda, A., \& Lillis, J. (2006). Acceptance and commitment therapy: Model, processes and outcomes. Behaviour Research and Therapy, 44(1), 1-25. https://doi.org/10.1016/j.brat.2005.06.006

İnandı, Y., \& Tunç, B. (2012). Kadın öğretmenlerin kariyer engelleri ile iş doyum düzeyleri arasındaki ilişki. Eğitim Bilimleri Araştırmaları Dergisi, 2(2), 203-222.

Javid, N., Ahmadi, A., Mirzaei, M., \& Atghaei, M. (2019). Effectiveness of solution-focused group counseling on the mental health of midwifery students. Revista Brasileira de Ginecologia e Obstetrícia, 41(8), 500-507. https://doi.org/10.1055/s-0039-1693741

Johnson, D. P., \& Whisman, M. A. (2013). Gender differences in rumination: A meta-analysis. Personality and Individual Differences, 55(4), 367-374. https://doi.org/10.1016/j.paid.2013.03.019

Karakuş, S., \& Akbay, S. E. (2020). Psikolojik Esneklik Ölçeği: Uyarlama, geçerlik ve güvenirlik çalışması. Mersin Üniversitesi Eğitim Fakültesi Dergisi, 16(1), 32-43. https://doi.org/10.17860/mersinefd.665406

Karatepe, H. T. (2010). Ruminatif düşünce biçimi ölçeğinin Türkçe uyarlamasl, geçerlik ve güvenirlik çalışması [Tıpta uzmanlık tezi]. Bakırköy Prof. Dr. Mazhar Osman Ruh Sağlığı ve Sinir Hastalıkları Eğitim ve Arştırma Hastanesi, Psikiyatri Kliniği..

Kasch, K. L., Rottenberg, J., Arnow, B. A., \& Gotlib, I. H. (2002). Behavioral activation and inhibition systems and the severity and course of depression. Journal of Abnormal Psychology, 111 (4), 589-597. https://doi.org/10.1037/0021-843x.111.4.589

Kashdan, T. B., \& Rottenberg, J. (2010). Psychological flexibility as a fundamental aspect of health. Clinical Psychology Review, 30(7), 865-878. https://doi.org/10.1016/j.cpr.2010.03.001 
Laaksonena, M. A., Knekta, P., Sares-Jäskea, L., \& Lindforsa, O. (2013). Psychological predictors on the outcome of short-term psychodynamic psychotherapy and Solution-Focused Therapy in the treatment of mood and anxiety disorder. European Psychiatry, 28(2), 117-124. https://doi.org/10.1016/j.eurpsy.2011.12.002

Luoma, J. B., \& Vilardaga, J. P. (2013). Improving therapist psychological flexibility while training acceptance and commitment therapy: A pilot study. Cognitive Behaviour Therapy, 42(1), 18. https://doi.org/10.1080/16506073.2012.701662

Luoma, J. B., Hayes, S. C., \& Walser, R. D. (2010). Learning ACT: An Acceptance \& Commitment Therapy skills-training manual for therapists. New Harbinger Publications, 60, 549-552.

Mautong, H., Gallardo-Rumbea, J. A., Alvarado-Villa, G. E., Fernández-Cadena, J. C., Andrade-Molina, D., Orellana-Román, C. E., \& Cherrez-Ojeda, I. (2021). Assessment of depression, anxiety and stress levels in the Ecuadorian general population during social isolation due to the COVID-19 outbreak: a cross-sectional study. BMC psychiatry,21(1), 1-15. https://doi.org/10.1186/s12888-021-03214-1

McCracken, L., Patel, S., \& Scott, W. (2018). The role of psychological flexibility in relation to suicidal thinking in chronic pain. European Journal of Pain, 22(10), 1774-1781. https://doi.org/10.1002/ejp.1273

Michalak, J., Hölz, A., \& Teismann, T. (2011). Rumination as a predictor of relapse in mindfulnessbased cognitive therapy for depression. Psychology and Psychotherapy: Theory, Research and Practice, 84(2), 230-236. https://doi.org/10.1348/147608310x520166

Nevanperä, N., Lappalainen, R., Kuosma, E., Hopsu, L., Uitti, J., \& Laitinen, J. (2013). Psychological flexibility, occupational burnout and eating behavior among working women. Open Journal of Preventive Medicine, 3(4). 355-361. https://doi.org/10.4236/ojpm.2013.34048

Noble, R. E. (2005). Depression in women. Metabolism, 54(5), 49-52. https://doi.org/10.1016/j.metabol.2005.01.014

Nolen-Hoeksema, S. (2000). The role of rumination in depressive disorders and mixed anxiety/depressive symptoms. Journal of Abnormal Psychology, 109(3), 504. https://doi.org/10.1037/0021-843x.109.3.504

Nolen-Hoeksema, S., Wisco, B. E., \& Lyubomirsky, S. (2008). Rethinking rumination. Perspectives on Psychological Science, 3(5), 400-424. https://doi.org/10.1111/j.17456924.2008.00088.x

Novella, J. K., Ng, K. M., \& Samuolis, J. (2020). A comparison of online and in-person counseling outcomes using solution-focused brief therapy for college students with anxiety. Journal of American College Health, 1-8. https://doi.org/10.1080/07448481.2020.1786101

Öcel, H. (2017). Meme kanseri tanısı almış çalışan kadınlarda damgalanma ve bilinçli farkındalık ile psikolojik iyi oluş arasındaki ilişkiler: Psikolojik esnekliğin düzenleyici rolü. Türk Psikoloji Dergisi, 32(80), 116-133.

Ögel, K. (2012). Farkındalık (ayrımsama) ve kabullenme temelli terapiler. HYB Basım Yayın.

Oliver, C., \& Charles, G. (2015). Which strengths-based practice? reconciling strengths-based practice and mandated authority in child protection work. Social Work, 60(2), 135-143. https://doi.org/10.1093/sw/swu058

Pakenham, K. I., Landi, G., Boccolini, G., Furlani, A., Grandi, S., \& Tossani, E. (2020). The moderating roles of psychological flexibility and inflexibility on the mental health impacts of COVID19 pandemic and lockdown in Italy. Journal of contextual behavioral science, 17, 109-118. https://doi.org/10.1016/j.jcbs.2020.07.003 
Plosker, R., \& Chang, J. (2014). A solution-focused therapy group designed for caregivers of stroke $\begin{array}{llll}\text { survivors. Journal of Systemic Therapies. 33(2), 49. } & \text { 35. }\end{array}$ https://doi.org/10.1521/jsyt.2014.33.2.35

Raes, F., \& Williams, J. M. G. (2010). The relationship between mindfulness and uncontrollability of ruminative thinking. Mindfulness, 1(4), 199-203. https://doi.org/10.1007/s12671-0100021-6

Şanal Karahan, F. (2016). Üniversite öğrencilerinde çözüm odaklı düşünmenin depresyon, anksiyete, stres ve psikolojik iyi oluş ile ilişsisi [Yayımlanmamış doktora tezi]. Necmettin Erbakan Üniversitesi.

Şanal Karahan, F., \& Hamarta, E. (2015). Çözüm Odaklı Envanter: Güvenirlik ve geçerlik çalışması. Ilköğretim Online, 14 (2), 1-13. https://doi.org/10.17051/io.2015.15313

Sarıçam, H. (2014). Çözüm odaklı kısa süreli yaklaşıma dayalı bir müdahale programının ruminasyon üzerinde etkisi [Yayımlanmamıș doktora tezi]. Sakarya Üniversitesi.

Shrout, P. E., \& Bolger, N. (2002). Mediation in experimental and nonexperimental studies: New procedures and recommendations. Psychological Methods, 7(4), 422-445. https://doi.org/10.1037/1082-989x.7.4.422

Smith, J. M., \& Alloy, L. B. (2009). A roadmap to rumination: A review of the definition, assessment, and conceptualization of this multifaceted construct. Clinical Psychology Review, 29(2), 116-128. https://doi.org/10.1016/j.cpr.2008.10.003

Sparrer, I. (2012). Çözüm odaklı yaklaşıma ve sistemik yapısal dizime giriş. (çev. E. Suvari Erol). Pan.

Stabbe, O. K., Rolffs, J. L., \& Rogge, R. D. (2019). Flexibly and/or inflexibly embracing life: Identifying fundamental approaches to life with latent profile analyses on the dimensions of the Hexaflex model. Journal of Contextual Behavioral Science, 12,106-118. https://doi.org/10.1016/j.jcbs.2019.03.003

Stange, J. P., Alloy, L. B., \& Fresco, D. M. (2017). Inflexibility as a vulnerability to depression: A systematic qualitative review. Clinical Psychology: Science and Practice, 24(3), 245-276. https://doi.org/10.1111/cpsp.12201

Yağmur, B. (2018). Üniversite öğrencilerinde bağlanma stilleri, ruminasyon ve depresyon düzeyi arasındaki ilişkinin incelenmesi [Yayımlanmamış yüksek lisans tezi]. Hasan Kalyoncu Üniversitesi.

Yapan, S. (2018). Depresyon ve anksiyete belirtilerinin yordayıcıları olarak ruminasyon, otomatik düşünceler, işlevsel olmayan tutumlar ve düşünce baskılama [Yayımlanmamış yüksek lisans tezi]. Hasan Kalyoncu Üniversitesi.

Yasinski, C., Hayes, A. M., Ready, C. B., Abel, A., Görg, N., \& Kuyken, W. (2020). Processes of change in cognitive behavioral therapy for treatment-resistant depression: psychological flexibility, rumination, avoidance, and emotional processing. Psychotherapy Research, 30(8), 983-997. https://doi.org/10.1080/10503307.2019.1699972 


\section{EXTENDED ABSTRACT}

\section{Introduction}

It has been observed in studies that ruminative thoughts, which manifest themselves when faced with problems, prevent the individual from using these resources and lead the individual to depression more (Harris, 2009; Sarıçam, 2014; Johnson \& Whisman, 2013). Psychological rigidity is the state of being unable to focus on the present and being in the here and now as a result of an individual's excessive preoccupation with painful and sad memories of the past, ruminations about them, and subsequent increased anxiety and worry about the future (Harris, 2009). On the other hand, psychological flexibility, which is the opposite of this, is the individual's realizing his feelings and thoughts in the face of the events he has experienced, contacting the moment he is in without being stuck on the past or the future, and evaluating the problems he encounters with realistic solutions (Luoma et al., 2010). In this context, when these concepts are examined, it has been noted that psychological flexibility has points of contact with rumination and solutionfocused thinking, and it has been seen that they are related to each other in different studies. In this study, it was aimed to examine the place of psychological flexibility between the variables of rumination and solution-focused thinking, which are related to each other. The main purpose of this research is to examine the mediating role of psychological flexibility in the relationship between rumination and solution-focused thinking in female teachers. Based on the results of the studies in the literature, rumination was considered as the independent variable, solution-focused thinking as the dependent variable, and psychological flexibility as the mediating variable. The hypotheses created for the purpose of the research are as follows: H1: There is a statistically significant negative correlation between rumination and psychological flexibility. H2: There is a statistically significant positive correlation between psychological flexibility and solution-focused thinking. H3: There is a statistically significant negative correlation between rumination and solution-focused thinking. H4: Psychological flexibility has a mediating role in the relationship between rumination and solution-focused thinking.

Women's employment in teachers is more intense than in other public institutions (Aksöz and Durkal, 2021). Many epidemiological studies have found that the lifetime prevalence of depressive disorder in women is almost twice that of men (Hammen, 2003; Mautong, et al, 2021; Noble, 2005). In a recent study, it was observed that both ruminative thinking style and depression levels of women were higher than men (Dawson et al., 2022). In addition to these, the results of studies dealing with the problems faced by female teachers in business life and the situations that hinder their career development also draw attention to the importance of the subject day by day (İnandı \& Tunç, 2012). In addition, it can be said that both work responsibilities and domestic and family responsibilities of female teachers have increased in distance education 
during the Covid-19 pandemic process. The level of influence of these and many similar situations on women, their methods of coping with problems, their awareness level, their approach to problems with a flexible or rigid perspective also varies. It has been thought that these variability may be related to the level of psychological flexibility (Luoma et al. 2010), which can be summarized as the individual's awareness of his feelings and thoughts in the face of the events he has experienced, his being in contact with the moment he is in without being stuck on the past or the future, and the ability to evaluate the problems he encounters with realistic solutions, and the necessity of examining the subject has arisen.

\section{Method}

The study group of the research consisted of 307 female teachers working in schools affiliated to the Ministry of National Education. Psychological Resilience Scale, Ruminative Thought Style Scale and Solution Focused Inventory were used as data collection tools. In the study, rumination was determined as the independent variable, solution-focused thinking as the dependent variable, and psychological flexibility as the mediating variable. This research was designed according to the relational screening design, in which the existence and degree of the relationship between the variables was examined. Mediation analyzes were performed on the basis of regression-based bootstrapping.

\section{Results}

As a result of the mediation analysis, it was seen that rumination predicted psychological flexibility and solution-focused thinking. In addition, it was found that psychological flexibility also predicted solution-focused thinking. When the indirect effect was examined, it was observed that the path coefficient between rumination and solution-focused thinking decreased with the inclusion of psychological flexibility, which is a mediating variable, in the model, in other words, psychological flexibility had a partial mediating role in the relationship between rumination and solution-focused thinking. In line with these results, it can be said that the negative effect of rumination on solution-focused thinking in female teachers can be reduced through psychological flexibility.

\section{Discussion \& Conclusion}

As a result, in this study, it was found that rumination affects the solution-focused thinking of female teachers both directly and through psychological flexibility. Based on this result, it seems possible to reduce the negative effect of ruminative thoughts of female teachers on their solutionfocused thinking and to increase the psychological flexibility levels of female teachers. For this reason, it is important to prioritize activities such as creating psychoeducational or psychological counseling groups on psychological flexibility that will increase the psychological flexibility levels 
of especially female teachers in schools, and raising awareness by informing about psychological flexibility. This study also found that rumination, together with psychological flexibility, explained $46 \%$ of the change in solution-focused thinking. This finding is important because it tests a model that makes significant contributions to the literature in dealing with activities that will reduce rumination and increase psychological flexibility in intervention programs designed to improve teachers' solution-focused thinking. Apart from this, it is thought that examining the mediation effect of different variables other than psychological flexibility that may affect the relationship between rumination and solution-focused thinking in this study will make important contributions to understanding the nature of solution-focused thinking, which is determined as the dependent variable of the research.

It should be noted that this study was conducted with a special sample of female teachers with a mean age of $35.41 \pm 8.00$ years and was based on the cross-sectional method. These results are limited to the specified method and working group framework. It is recommended to test the relevant variables using longitudinal or experimental methods on different samples and age groups in order to examine the subject in depth. 